\title{
Comparative haemodynamic and peripheral vasodilator effects of oral and chewable isosorbide dinitrate in patients with refractory congestive cardiac failure ${ }^{1}$
}

\author{
JAIME FIGUERAS, WILLIAM R. TAYLOR, TAKESHI OGAWA, JAMES S. \\ FORRESTER, BRAMAH N. SINGH, AND H. J. C. SWAN \\ From the Department of Cardiology, Cedars-Sinai Medical Center, and the Department of Medicine, \\ UCLA School of Medicine, Los Angeles, California, USA
}

SUMmaRY The effects of oral $(30 \mathrm{mg})$ and chewable $(10 \mathrm{mg})$ isosorbide dinitrate on haemodynamics, venous capacitance, and calf blood flow were compared in a double-blind trial in 18 patients with refractory chronic congestive heart failure with pulmonary artery end-diastolic pressures $\geqslant 18 \mathrm{mmHg}$. Cardiac output and right heart pressures were measured with a Swan-Ganz thermodilution catheter, arterial pressure through an indwelling radial artery cannula, and venous capacitance and calf blood flow by vascular occlusion plethysmography. Both agents reduced pulmonary artery end-diastolic pressures $>10$ per cent in 15 patients ('responders') but by $\leqslant 10$ per cent in 3 others ('non-responders'). In the responders, both agents produced significant decreases in mean arterial pressure, in pulmonary artery end-diastolic pressures, and in mean right atrial pressure. Oral (but not chewable) isosorbide dinitrate produced a significant increase in cardiac index and stroke volume index while decreasing systemic vascular resistance and heart rate. Both agents increased venous capacitance significantly but without a comparable effect on calf blood flow. The onset of action for both agents was apparent within 10 minutes; the peak effect, however, occurred significantly earlier for the chewable isosorbide dinitrate, whereas the duration of action was longer for oral isosorbide dinitrate. The overall data thus indicate that both oral and chewable isosorbide dinitrate may have significant effects on vascular capacitance bed but because of its more pronounced effect on ventricular function and its more prolonged duration of action, oral isosorbide dinitrate appears to be the preferred agent for protracted oral treatment in congestive cardiac failure.

The effects of peripheral vasodilators upon cardiac haemodynamics have been studied extensively since the recognition of their efficacy in patients with heart failure secondary to acute myocardial infarction in the early 1970's (Majid et al., 1971; Franciosa et al., 1972; Gold et al., 1972; Chatterjee et al., 1973; Cohn, 1973). After the initial documentation of the profound haemodynamic effects of intravenous vasodilators, attention has focused recently on the use of oral and sublingual preparations (Franciosa et al., 1974; Gray et al., 1975; Mikulic et al., 1975; Chatterjee et al., 1976; Kovick et al.,

${ }^{1}$ Supported in part by SCOR Grant, National Institutes of Health, Bethesda, Maryland, USA.

Received for publication 3 April 1978
1976; Mantle et al., 1976; Williams et al., 1977) as potential agents for the long-term management of cardiac failure, particularly in patients having satisfactory responses to intravenous agents in acute studies. Most prominent of this class of agents are hydralazine (Chatterjee et al., 1976) and nitrates (Franciosa et al., 1974; Gray et al., 1975; Mikulic et al., 1975; Kovick et al., 1976; Mantle et al., 1976; Williams et al., 1977). Though both these regimens have been found to improve symptoms as well as cardiac haemodynamics (Franciosa et al., 1974; Gray et al., 1975; Mikulic et al., 1975; Williams et al., 1977) in congestive heart failure, no adequately controlled clinical studies in which the time of onset, duration of effect, haemodynamic potency, and mechanism of action of different 
preparations of vasodilators were compared in the same individual have so far been reported. The present study has, therefore, served to compare and define those important clinical variables with two of the potentially most useful agents, oral and chewable isosorbide dinitrate. Our results not only confirm and extend the results of the previous haemodynamic studies for these agents, but also indicate that substantial differences between them exist while providing an insight into the potential mechanism for the lack of expected haemodynamic responses found in the non-responders.

\section{Patient selection and methods}

The study was undertaken with 18 patients, 17 men and 1 woman (mean age 67 years, range 21 to 82 years) who had congestive heart failure (functional class III-IV, New York Heart Association classification) as judged by clinical as well as radiological criteria. All patients considered refractory to conventional therapy consisting of adequate doses of digitalis and diuretics had been on bed rest for at least 3 days before entry into the study. Diuretics were discontinued at least 12 hours before the study. Only those patients who had a pulmonary artery diastolic pressure (PADP) or capillary wedge pressure (PCP) $\geqslant 18 \mathrm{mmHg}$ (see below) were included in the study.

The cause of heart failure was attributed to coronary artery disease in 12 patients, hypertensive heart disease in 1, peripartum cardiomyopathy in 1, alcoholic cardiomyopathy in another, and idiopathic cardiomyopathy in the remaining 3. Physical findings, with or without the presence of significant ' $V$ ' waves in the wedge pressure tracings, consistent with mitral regurgitation were encountered in 6 patients. There were no other valve lesions. Acute myocardial infarction was excluded in each instance by the conventional electrocardiographic and serum enzyme criteria. Three of the 18 patients had been previously treated with sublingual isosorbide dinitrate.

Intra-arterial pressure (AP) was measured through a 19 gauge, 2-inch indwelling catheter inserted percutaneously into the radial artery. Pulmonary artery (PA), pulmonary capillary (PC), and right atrial (RAP) pressures were measured through a no. 7 Fr Swan-Ganz thermodilution catheter placed via an antecubital vein through a cut-down, or percutaneously through the internal jugular vein. Cardiac output (CO) was measured in triplicate by the thermodilution technique (Ganz and Swan, 1972).

In 12 patients, venous capacitance (VC) and calf blood flow (CBF) were measured. Venous capacitance was measured in one of the lower extremities by the equilibrium method using a pneumatic plethysmograph (Vyden et al., 1974), with a venous occluding pressure of $30 \mathrm{mmHg}$. Calf blood flow was also measured by plethysmography with a distal occlusive pressure of $200 \mathrm{mmHg}$.

Derived haemodynamic indices were calculated from the measured variables as follows: cardiac index $(\mathrm{CI})=\mathrm{CO} /$ body surface area $\left(1 / \mathrm{min}\right.$ per $\left.\mathrm{m}^{2}\right)$; stroke volume index $(\mathrm{SI})=$ stroke volume $(\mathrm{SV}) /$ body surface area $\left(\mathrm{ml} / \mathrm{m}^{2}\right.$ per beat); systemic vascular resistance $(\mathrm{SVR})=80 \times(\overline{\mathrm{AP}}-\overline{\mathrm{RAP}})$ CO $(1 / \mathrm{min})$ (dynes $\left.\mathrm{s}^{-1} \mathrm{~cm}^{-5}\right)$; stroke work index $(\mathrm{SWI})=(\overline{\mathrm{AP}}-\overline{\mathrm{PCP}}$ or $\mathrm{PADP}) \times \mathrm{SI} \times$ $0.0136\left(\mathrm{~g} / \mathrm{m}^{2}\right.$ per beat); and pulmonary vascular resistance $(\mathrm{PVR})=80 \times(\overline{\mathrm{PA}}-\overline{\mathrm{PCP}} \mathrm{mmHg}) / \mathrm{CO}$ $1 / \min \left(\right.$ dynes s $\mathrm{s}^{-1} \mathrm{~cm}^{-5}$ ).

\section{DESIGN OF STUDY}

Baseline measurements were obtained every 30 minutes for a minimum of one hour. They were considered stable only when pulmonary artery

Table Peak and duration of action of chewable $(10 \mathrm{mg})$ and oral $(30 \mathrm{mg})$ isosorbide dinitrate in patients $(n=15)$ with congestive heart failure

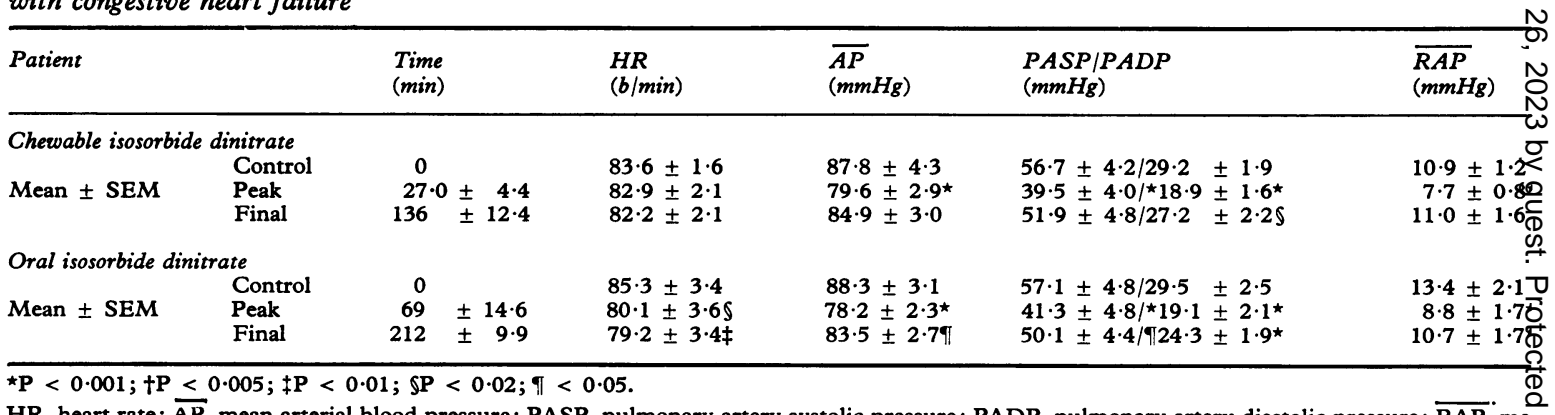

HR, heart rate; $\overline{A P}$, mean arterial blood pressure; PASP, pulmonary artery systolic pressure; PADP, pulmonary artery diastolic pressure; $\overline{\mathrm{RAP}}$, m $\mathrm{Q}$ right atrial pressure; CI, cardiac index; SI, stroke volume index; SWI, stroke work index; SVR, systemic vascular resistance; PVR, pulmonary vascK resistance: VC, venous capacitance. 
diastolic pressure or pulmonary capillary pressure and vital capacity were within 10 per cent in 2 consecutive measurements. As soon as the stable baseline was reached, either chewable isosorbide dinitrate, $10 \mathrm{mg}$, or oral isosorbide dinitrate, $30 \mathrm{mg}$, was administered. For a chewable compound, the patient was instructed to chew the tablet under supervision of a physician for a minimum of 2 minutes. For the oral compound, the patient was instructed to swallow the tablets. In order to establish a double-blind format, each time the patient had to swallow 3 tablets $(30 \mathrm{mg}$ oral isosorbide dinitrate or placebo) and to chew one tablet (placebo or $10 \mathrm{mg}$ chewable isosorbide dinitrate). Subsequently, measurements of all variables were taken at 15 -minute intervals for the first hour and every 30 minutes thereafter for a minimum of 2 hours and a maximum of 4 hours until the value of PADP had returned within 10 per cent of control level. Thereafter, the same procedure was repeated for the second drug. If the pulmonary artery diastolic pressure had not returned to a value $\geqslant 18 \mathrm{mmHg}$ after the first agent, the study with the second drug was delayed until this value was achieved.

The dose of chewable or oral isosorbide dinitrate used in the study was chosen to produce haemodynamic effects of a comparable magnitude as indicated in previous reports (Franciosa et al., 1974; Mikulic et al., 1975). Statistical analyses were carried out by the use of Student's $t$ tests for paired and unpaired data.

\section{Results}

Patients in whom pulmonary artery diastolic pressure had decreased by more than 10 per cent relative to their control values were designated as responders, whereas those who failed to respond to oral isosorbide dinitrate (3 patients) and/or to chewable isosorbide dinitrate ( 3 patients) were designated as non-responders.

\section{RESPONDERS: TIME OF ONSET, PEAK}

EFFECT, AND DURATION OF ACTION

There were no significant differences between the two sets of control values though the baseline cardiac index and systemic vascular resistance for the oral isosorbide dinitrate were somewhat lower and higher, respectively, than those for the chewable isosorbide dinitrate (Table). The onset of action of the haemodynamic changes was usually apparent during the first 15 minutes for both drugs, the effects with chewable isosorbide dinitrate being noticeable earlier than those after oral isosorbide dinitrate which frequently occurred within the first 7 minutes of drug ingestion.

The differences between the effects of oral and chewable isosorbide dinitrate with respect to measured and derived haemodynamic variables are presented in the Table and Fig. 1-3. The peak haemodynamic effects occurred significantly earlier with chewable isosorbide dinitrate (27 vs. $69 \mathrm{~min}$, $P<0.01)$. Compared with the control values, the peak changes were statistically significant and of comparable magnitude for both oral and chewable isosorbide dinitrate with respect to intra-arterial pressure: 11.4 per cent vs. 9.3 per cent (Fig. 1); right atrial pressure: 34.3 per cent vs. 29.4 per cent (Fig. 2); pulmonary artery systolic pressure: $27 \cdot 7$ per cent vs. $30 \cdot 3$ per cent; pulmonary artery diastolic pressure: 35.3 per cent vs. $35 \cdot 3$ per cent (Fig. 2); pulmonary vascular resistance: 37.8 per cent vs. 33.5 per cent, respectively. Both agents also increased stroke work index. However, only the oral isosorbide dinitrate produced a significant increase in cardiac index $(14.8 \%)$ and stroke index $(19.6 \%$; Fig. 3), more significant improvement in left ventricular function (Fig. 4). Only isosorbide dinitrate also produced a decrease in systemic

\begin{tabular}{|c|c|c|c|c|c|}
\hline 2 per $\left.m^{2}\right)$ & $\begin{array}{l}S I \\
\left(m l / b \text { per } m^{2}\right)\end{array}$ & $\begin{array}{l}S W I \\
\left(g m / b \text { per } m^{2}\right)\end{array}$ & $\begin{array}{l}\text { SVR } \\
\text { dynes } \mathrm{s}^{-1} \mathrm{~cm}^{-5}\end{array}$ & $\begin{array}{l}P V R \\
\text { dynes } \mathrm{s}^{-1} \mathrm{~cm}^{-\mathrm{s}}\end{array}$ & $\begin{array}{l}V C \\
\mathrm{ml} / 100 \mathrm{ml}\end{array}$ \\
\hline $\begin{array}{l} \pm 0.16 \\
\pm 0.11 \\
\pm 0.16\end{array}$ & $\begin{array}{l}24 \cdot 9 \pm 2 \cdot 1 \\
25 \cdot 9 \pm 1 \cdot 5 \\
24 \cdot 1 \pm 2 \cdot 2\end{array}$ & $\begin{array}{l}19.5 \pm 2.8 \\
21.8 \pm 2.29 \\
19.5 \pm 2.4\end{array}$ & $\begin{array}{l}1612 \pm 90 \\
1515 \pm 71 \\
1721 \pm 141\end{array}$ & $\begin{array}{l}266 \pm 36 \\
177 \pm 26^{\star} \\
289 \pm 64\end{array}$ & $\begin{array}{l}0.53 \pm 0.42 \\
0.68 \pm 0.54 \pi \\
0.51 \pm 0.14\end{array}$ \\
\hline $\begin{array}{l} \pm 0.12 \\
\pm 0.129 \\
\pm 0.10\end{array}$ & $\begin{array}{l}22.5 \pm 1.9 \\
26.9 \pm 2.0 \ddagger \\
25.7 \pm 1.87\end{array}$ & $\begin{array}{l}18 \cdot 3 \pm 2 \cdot 0 \\
21 \cdot 7 \pm 1 \cdot 9 \$ \\
21 \cdot 1 \pm 2 \cdot 29\end{array}$ & $\begin{array}{l}1819 \pm 122 \\
1542 \pm 86 t \\
1782 \pm 113\end{array}$ & $\begin{array}{l}323 \pm 54 \\
201 \pm 36 t \\
271 \pm 48\end{array}$ & $\begin{array}{l}0.42 \pm 0.33 \\
0.73 \pm 0.661 \\
0.58 \pm 0.19\end{array}$ \\
\hline
\end{tabular}



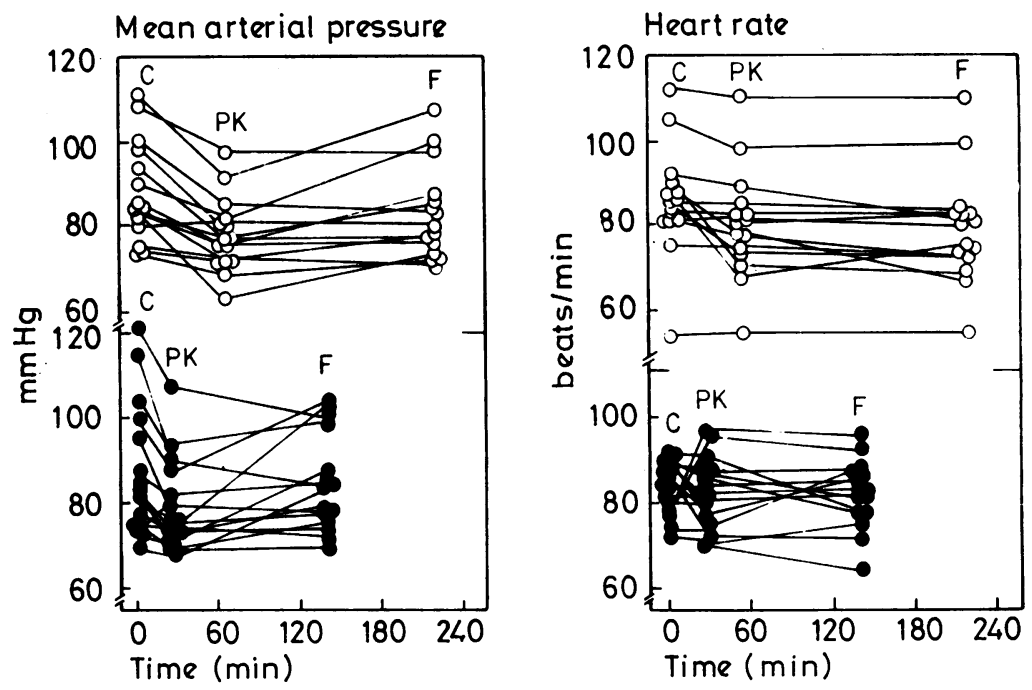

- Oral ID

- Chewable ID

Fig. 1 Effects of oral and chewable isosorbide dinitrate (ID) on mean arterial pressure and heart rate. Note that the peak (PK) effects are earlier with the chewable preparation than with the oral. $F=$ final set of values after each drug intervention.

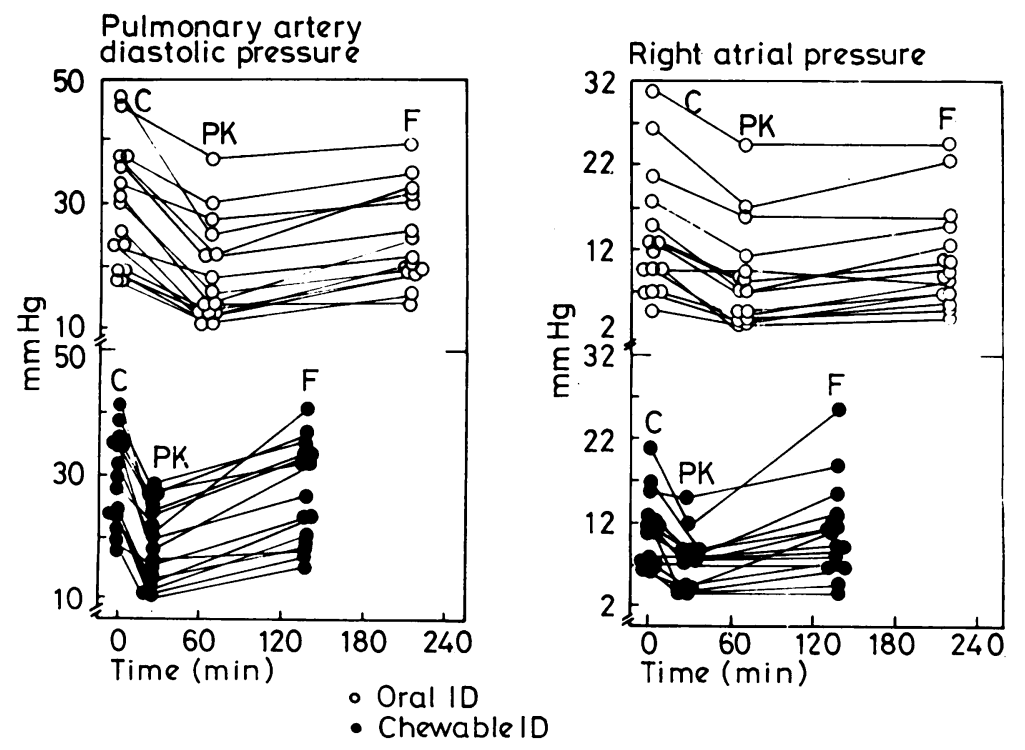

Fig. 2 Changes in pulmonary artery diastolic pressure and right atrial pressure after oral and chewable ID. See text for comments. 

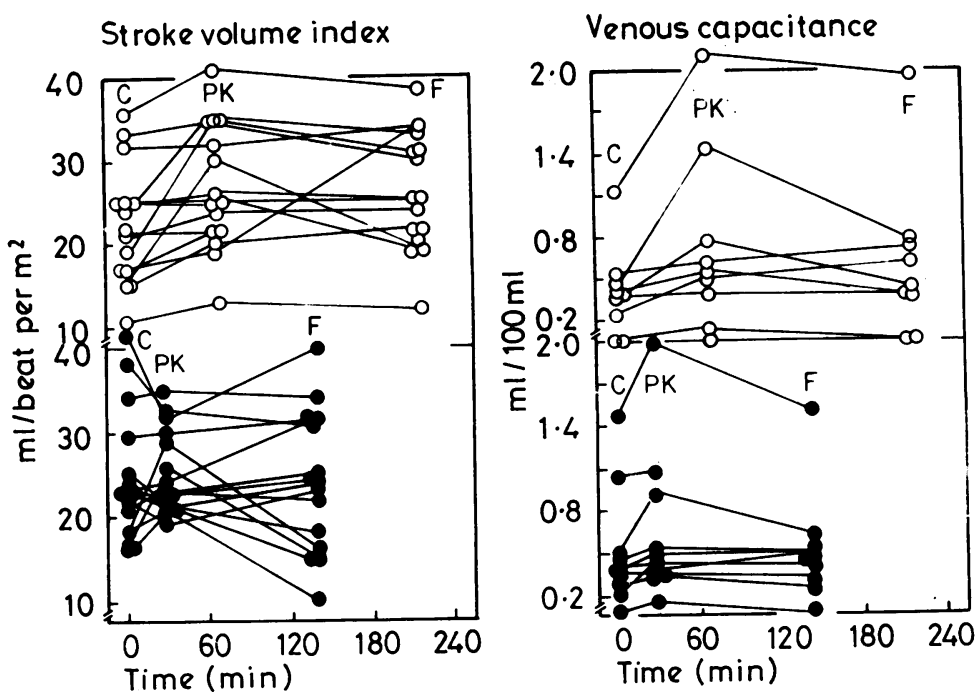

- Oral ID

- Chewable ID

Fig. 3 Changes in stroke volume index and in venous capacitance after oral and chewable ID. See legend for Fig. 1 for the meaning of abbreviations, and theltext for discussion.
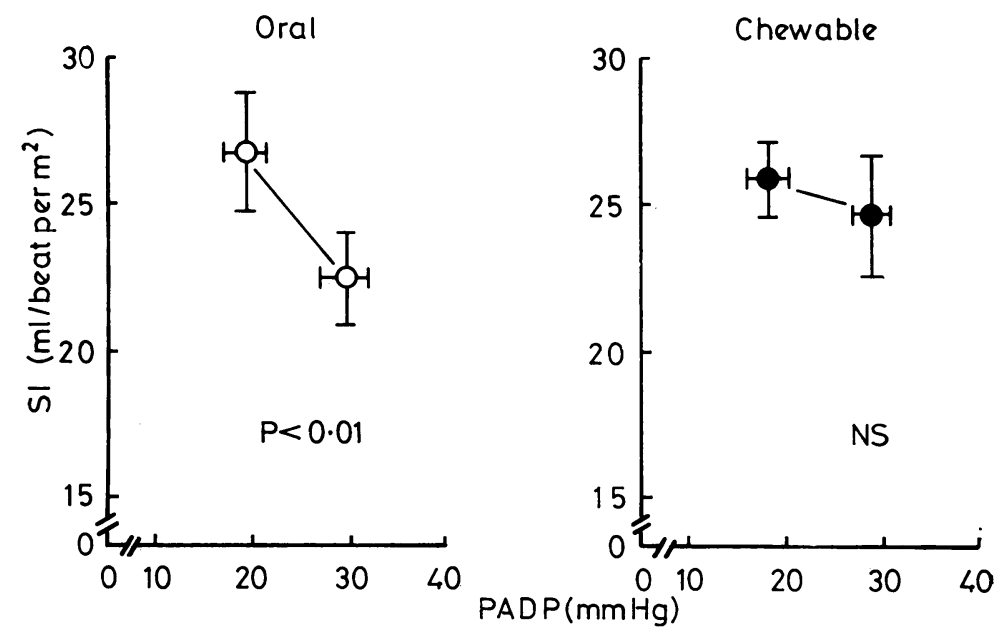

Fig. 4 Improvement in left ventricular function in 15 patients with refractory congestive heart failure as shown by a significant increase in stroke volume index (SI) and concurrent reduction in left ventricular filling pressure, expressed by pulmonary artery diastolic pressure, was only achieved with oral ID (30 mg) (left panel). Chewable ID (10 mg) (right panel) had no significant effect upon SI.

vascular resistance $(15 \cdot 2 \%)$ and heart rate $(6 \cdot 1 \%)$ (Fig. 1). Venous capacitance was significantly increased by both agents, the changes tending to be more pronounced with oral isosorbide dinitrate $(75 \%$ vs. $29 \%$; Fig. 3) though the differences between the chewable isosorbide dinitrate and oral isosorbide dinitrate did not reach a level of statistical significance. Changes in calf blood flow were variable and insignificant with both preparations.

The duration of action was significantly longer 

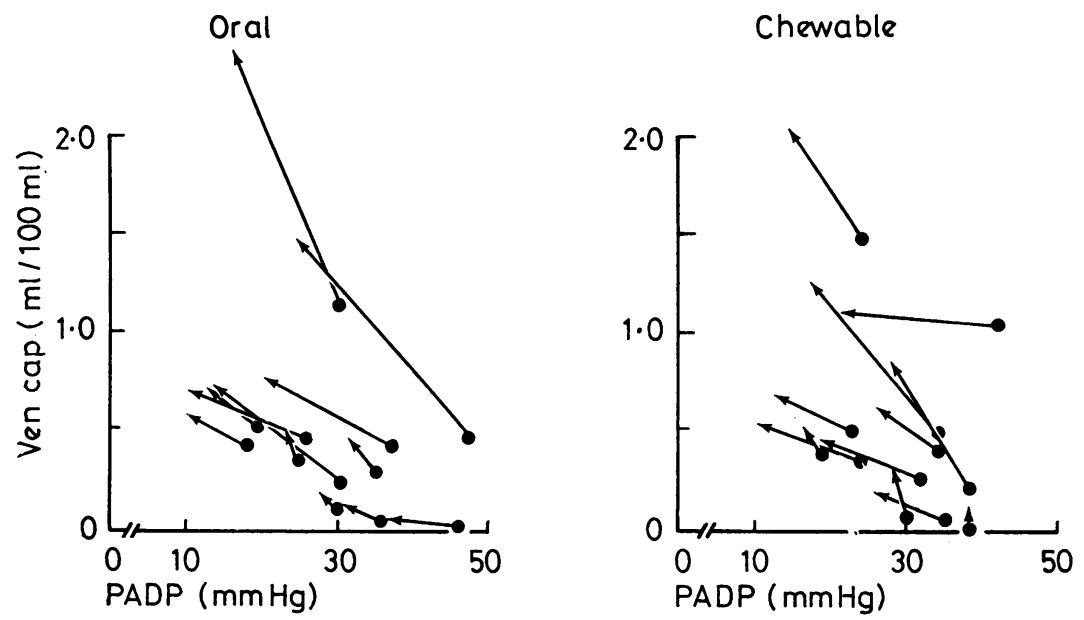

Fig. 5 The effects of $30 \mathrm{mg}$ of oral ID (left panel) and $10 \mathrm{mg}$ of chewable ID (right panel) on venous capacitance and pulmonary artery diastolic pressure $(P A D P)$ in 12 patients with refractory congestive heart failure are illustrated in this figure. The magnitude of the effect of these two agents on these two indices was very similar. The graph shows that those patients with very decreased venous capacitance had a tendency to have the smallest changes in both $P A D P$ and venous capacitance.

for oral isosorbide dinitrate (212 vs. $136 \mathrm{~min}$, $P<0.001$; Table). In addition, in 9 of the 15 patients given oral isosorbide dinitrate, pulmonary artery diastolic pressure had not returned to within 10 per cent of the control values after 4 hours, whereas this occurred with only 4 patients given chewable isosorbide dinitrate.

\section{NON-RESPONDERS}

Even though the pulmonary artery diastolic pressure did not decrease more than 10 per cent in all patients in this group, they exhibited a uniform though small decrease in pulmonary vascular resistance. In 4 , this was attributed to a moderate increase in cardiac output and in 2, to a moderate decrease in mean pulmonary artery pressure. Only 1 patient failed to respond to both agents. There were no common haemodynamic or clinical features among these patients, except for their tendency to have a substantially lower venous capacitance compared to the responders. As illustrated in Fig. 5, patients who had the lowest initial venous capacitance had a tendency to exhibit the smallest change in both venous capacitance and pulmonary artery diastolic pressure after isosorbide dinitrate.

\section{Discussion}

The data from our double-blind comparative haemodynamic studies with oral and chewable isosorbide dinitrate in the same patients have indicated that both agents can produce sustained and comparable reductions in the pulmonary capillary wedge pressure, the main determinant of pulmonary congestion; these findings agree with previous observations (Franciosa et al., 1974; Mikulic et al., 1975; Bussmann et al., 1977; Williams et al., 1977). However, in the present study an important difference in the effects between oral and chewable isosorbide was found with respect to changes in stroke volume index and systemic vascular resistance. Administration of oral isosorbide resulted in a 20 per cent increase in stroke volume index and a 15 per cent decrease in systemic vascular resistance whereas the effect of chewable isosorbide was negligible. Williams et al. (1977) who noted a consistent decrease in left ventricular filling pressure using oral isosorbide failed to document significant increases in stroke volume index or decreases in systemic vascular resistance, except in patients whose pulmonary capillary pressure had not fallen to levels below $12 \mathrm{mmHg}$ after drug administration. Even though the oral dose used in the present study was larger than that $(20 \mathrm{mg}$ ) given by Williams and his colleagues, the effect on the left ventricular filling pressure was comparable. The differences between the two sets of data suggest that the type of response observed may be dose-dependent, and that a larger dose of oral isosorbide dinitrate may induce a more con- 
sistent afterload reduction and consequent functional improvement. Franciosa et al. (1974) also reported a decrease in left ventricular filling pressure after oral isosorbide dinitrate, though the observed change in their study was smaller than that in ours $(25 \%$ vs. $35 \%)$. Systemic vascular resistance and other flow-dependent variables were not measured in their study. Bussmann et al. (1977), treating patients with left ventricular failure secondary to an acute myocardial infarction, found a similar fall in left ventricular filling pressure using the same total dose of oral isosorbide dinitrate $(30 \mathrm{mg})$, though it was administered in two doses (10 and $20 \mathrm{mg}$ ) at 30-minute intervals. The major haemodynamic changes were apparent after the initial dose $(10 \mathrm{mg})$. In their study the criterion for left ventricular failure was a left ventricular filling pressure greater than $20 \mathrm{mmHg}$, and it was only among this group that a fall in left ventricular filling pressure was associated with an increase in cardiac output.

A significant decrease in heart rate after oral but not chewable isosorbide dinitrate, observed in our study as well as in those of others in patients with congestive heart failure using nitroprusside (Franciosa et al., 1972) or glyceryl trinitrate (Gold et al., 1972), is of particular interest. The decline in heart rate which occurred despite a fall in blood pressure has not been a consistent finding, however, in patients without heart failure (Kasparian et al., 1975; Bussmann et al., 1977).

In the only previous study on the haemodynamic effects of chewable isosorbide dinitrate in patients with congestive heart failure which did not include flow-related measurements, Mikulic et al. (1975) found a similar fall in left ventricular filling pressure but they did not find a significant change in arterial pressure. This difference was probably related to the much lower resting blood pressure in their patient population $(106 / 78$ vs. $133 / 66)$.

The differences in the response in stroke index and systemic vascular resistance induced by the two agents further illustrate the difficulties inherent in the interpretation of data from comparative drug studies in man. Usually such studies are conducted using drugs of differing chemical structures, and dissimilar responses are often attributed to differences in the intrinsic pharmacological properties of the agents themselves. Our study shows that substantial differences in response may be obtained in the same patient with the same drug at approximately comparable doses, when the mode of administration is altered. Whether this difference is in fact related to the route of drug administration cannot, however, be ascertained from the results of the present study.

In addition to the differences in the effects on stroke volume and systemic vascular resistance, the two agents were found to -be substantially different in the peak effect and overall duration of action. The onset of action of chewable isosorbide was invariably apparent within 10 minutes of drug administration with a peak activity being attained by 27 minutes, thus making it a very suitable compound for acute administration in patients in hospital. Since its mean duration of action is only 136 minutes, which is very similar to that reported for sublingual isosorbide dinitrate (Gray et al., 1975; Kovick et al., 1976), it is obviously of limited value for longterm treatment of congestive cardiac failure. In contrast, oral isosorbide had a similar onset of action, starting within 15 to 20 minutes but reaching peak activity in 69 minutes with its effect being sustained for at least $3 \frac{1}{2}$ hours; these characteristics of the drug, as have also been noted by previous investigators (Franciosa et al., 1974; Williams et al., 1977), greatly enhance clinical usefulness for long-term treatment.

Our measurements of peripheral vascular functions undertaken in association with the haemodynamic studies in 12 of the 18 patients suggest that both agents might exert their major effect by peripheral venodilatations. In 6 of 9 responders to oral isosorbide dinitrate and in 6 of the 10 responders to chewable isosorbide dinitrate, venous capacitance was near normal before drug administration; it increased significantly after both oral and chewable isosorbide dinitrate The mean increases in venous capacitance tended to parallel the decreases in left ventricular filling pressure. In contrast, venous capacitance was abnormally low in all the patients who exhibited little or no response to drug administration. The arterial flow to the lower limbs showed little change in both responders as well as nonresponders to the drugs. It is of course possible that additional specific vascular beds may also be particularly responsive to the vasodilator action of isosorbide. The dramatic fall in pulmonary vascular resistance and the fall in pulmonary artery systolic pressure, often orcurring even in the absence of changes in left ventricular filling pressure, may suggest a direct vasodilator effect of the nitrate on the pulmonary vasculature as has been found with glyceryl trinitrate (Ferrer et al., 1966). Furthermore, the increase in cardiac index and stroke index induced by oral isosorbide, despite a consistent decline in arterial pressure, is suggestive of a concomitant element of afterload reduction (Cohn, 1973).

Although limited, these data suggest that the failure of chewable as well as oral isosorbide to induce the expected response in the presence of severe heart failure in certain patients may be 
related to the status of venous capacitance at the time of drug administration; if such were the case, these studies may be helpful in selecting patients who might derive benefit from protracted vasodilator therapy in recalcitrant congestive cardiac failure. The data have indicated that in a substantial number of patients, isosorbide dinitrate may produce a beneficial effect on haemodynamic functions lending further support for the use of peripheral vasodilators in the treatment of severe congestive cardiac failure. Though both the chewable and the oral preparation are both effective in reducing pulmonary capillary pressure in cardiac decompensation, oral isosorbide appears to have substantial advantages for outpatient use, especially in relation to its prolonged duration of action.

\section{References}

Bussmann, W., Löhner, J., and Kaltenbach, M. (1977). Orally administered isosorbide dinitrate in patients with and without left ventricular failure due to acute myocardial infarction. American fournal of Cardiology, 39, 91-96.

Chatterjee, K., Parmley, W. W., Ganz, W., Forrester, J. S., Walinsky, P., Crexells, C., and Swan, H. J. C. (1973). Hemodynamic and metabolic responses to vasodilator therapy in acute myocardial infarction. Circulation, 48, 1183-1193.

Chatterjee, K., Parmley, W. W., Massie, B., Greenberg, B., Werner, J., Klausner, S., and Norman, A. (1976). Oral hydralazine therapy for chronic refractory heart failure. Circulation, 54, 879-883.

Cohn, J. N. (1973). Vasodilator therapy for heart failure. The influence of impedance on left ventricular performance. Circulation, 48, 5-8.

Ferrer, M. I., Bradley, S. E., Wheeler, H. O., Enson, Y., Preisig, R., Brickner, P. W., Conroy, R. J., and Harvey, R. M. (1966). Some effects of nitroglycerin upon the splanchnic, pulmonary, and systemic circulations. Circulation, 33, 357-373.

Franciosa, J. A., Ghiha, N. M., Limas, C. J., Rodriguera, E., and Cohn, J. N. (1972). Improved left ventricular function during nitroprusside infusion in acute myocardial infarction. Lancet, 1, 650-654.
Franciosa, J. A., Mikulic, E., Cohn, J. N., Hose, E., and Fabie, A. (1974). Haemodynamic effects of orally administered isosorbide dinitrate in patients with congestive heart failure. Circulation, 50, 1020-1024.

Ganz, W., and Swan, H. J. C. (1972). Measurement of blood flow by thermodilution. American fournal of Cardiology, 29, 241-246.

Gold, H. K., Leinbach, R. C., and Sanders, C. A. (1972). Use of sublingual nitroglycerin in congestive failure following acute myocardial infarction. Circulation, 46, 839-845.

Gray, R., Chatterjee, K., Vyden, J. K., Ganz, W., Forrester, J. S., and Swan, H. J. C. (1975). Hemodynamic and metabolic effects of isosorbide dinitrate in chronic congestive heart failure. American Heart fournal, 90, 346-352.

Kasparian, H., Wiener, L., Duca, P. R., Gottlieb, R. S., and Brest, A. N. (1975). Comparative hemodynamic effects of placebo and oral isosorbide dinitrate in patients with significant coronary artery disease. American Heart fournal, 90, 68-74.

Kovick, R. B., Tillisch, J. H., Berens, S. C., Bramc witz, A. D., and Shine, K. I. (1976). Vasodilator therapy for chronic left ventricular failure. Circulation, 53, 322-328.

Majid, P. A., Sharma, B., and Taylor, S. H. (1971). Phentolamine for vasodilator treatment of severe heart failure. Lancet, 2, 719-724.

Mantle, J. O., Russell, R. O., Jr., Moraski, R. E., and Rackley, C. E. (1976). Isosorbide dinitrate for the relief of severe heart failure after myocardial infarction. American fournal of Cardiology, 37, 263-268.

Mikulic, E., Franciosa, J. A., and Cohn, J. N. (1975). Comparative hemodynamic effects of chewable isosorbide dinitrate and nitroglycerin in patients with congestive heart failure. Circulation, 52, 477-482.

Vyden, J. K., Nagasawa, K., Graettinger, W., Marcus, H. S., Groseth-Dittrich, M., and Swan, H. J. C. (1974). The effects of transfemoral catheterization on blood flow in the extremities. Circulation, 50, 741-746.

Williams, D. O., Bommer, W. J., Miller, R. R., Amsterdam, E. A., and Mason, D. T. (1977). Hemodynamic assessment of oral peripheral vasodilator therapy in chronic congestive heart failure: prolonged effectiveness of isosorbide dinitrate. American fournal of Cardiology, 39, 84-90.

Requests for reprints to Publication Office, Department of Cardiology, Cedars-Sinai Medical Center, 8700 Beverly Boulevard, Los Angeles, California 90048, USA. 